\title{
INFLUENCE OF CRITICAL INFRASTRUCTURE ON ENTERPRISE ECONOMIC SECURITY
}

This article deals with critical infrastructure and its influence on enterprise economic security. In the introduction, the sectors of critical infrastructure from the point of view of the European Union, Czech Republic and Slovak Republic are characterized. Attention is paid to individual links between the elements of critical infrastructure and the enterprise. Subsequently, enterprise economic security, fundamental factors participating in its creation, and threats disturbing it with emphasis on critical infrastructure failure are discussed. The final part of this article presents possible impacts of critical infrastructure failure on the enterprise economic security.

Keywords: Critical infrastructure, enterprise, economic security, threats, failure.

\section{Introduction}

The current society is more and more dependent on the system arrangement and services provided. One of the relevant factors of a prosperous society is also a functional infrastructure [1]. It is inevitable not only for the citizens to be satisfied but also for the activity of many enterprises. Its disruption would result in a whole range of negative impacts in all manufacturing and non-manufacturing lines of business. A certain part of this infrastructure is even of such importance that it is called critical infrastructure [2]. The impacts of its disruption or failure would be so extensive that even the existence of some companies could be threatened.

\section{Critical infrastructure and its influence on enterprise activity}

The critical infrastructure represents for each country a summary of strategically important elements and subjects whose disruption or destruction would have a serious impact on the interests protected by the state, i.e. security of the country, economy and basic needs of the inhabitants necessary for life [2]. While the state security and ensuring the life essentials are exclusively in the management of the state, the economic security is ensured by the state only partially. The state is responsible exclusively for the macroeconomic security while the microeconomic security is created, first of all, by the subjects themselves [3]. In the following text our attention will be aimed especially at the enterprises and their relation to the critical infrastructure.

The critical infrastructure of the EU is created by sectors which can be classified as European and national ones. The European sectors are unified for all member states and include energy (electricity, oil, gas) and transport (road transport, rail transport, air transport, inland waterways transport, ocean and short-sea shipping and ports) [2]. Contrary to this, the national sectors were defined by each member state separately based on its need reflecting the current security environment (e.g. [4] and [5]). However, generally we can say that the structure of these sectors is very similar in all countries and includes especially the following sectors:

- communication and information systems (information system and networks),

- financial market (banking and insurance sector),

- emergency services (integrated emergency system, monitoring networks),

- water economy (water treatment and supplying with drinking water),

- industry (chemical, metallurgical, pharmaceutical),

- food industry (crop farming and livestock production),

- health care.

\footnotetext{
* ${ }^{1}$ Stanislava Strelcova, ${ }^{2}$ David Rehak, ${ }^{3}$ David E. A. Johnson

${ }^{1}$ Faculty of Security Engineering, University of Zilina, Slovakia

${ }^{2}$ VSB - Technical University of Ostrava, Faculty of Safety Engineering, Czech Republic

${ }^{3}$ Missouri State University, Department of Political Science, USA

E-mail: Stanislava.Strelcova@fbi.uniza.sk
} 
The relation of the critical infrastructure (CI) and the enterprise can be expressed through individual links which arise between them. The basic classification of these links results from their character and includes the unilateral links which represent the influence of the $\mathrm{CI}$ sector on the enterprise and the dependence of the enterprise on the CI sector and bilateral links consisting in the dependence of the CI sector and the enterprise.

Due to the extent of the area being solved we will concentrate on a medium-sized manufacturing industrial enterprise (e.g. a chemical factory). At the same time it is necessary to draw your attention to the fact that the enterprise can be also part of the critical infrastructure (e.g. a nuclear power plant), however, such a type of enterprise is not the subject of our article. The graphical depiction of this relation is obvious from Fig. 1.

The figure shows that some sectors of the critical infrastructure affect significantly the enterprise activities or the enterprise is dependent on them. This influence or dependence can be so fundamental in some sectors (e.g. energy, transport) that the impacts of their failure can disrupt the economic security of the enterprise.

\section{Enterprise economic security}

When we implement a modern approach to security, the economic aspect of maintaining the system (social, technical, environmental,...) comes to foreground in such a state where it enables fulfilling the stated functions as well as their development which results in developing a new security component - the economic security.

Zeman et al. [6] define the economic security as a state where the economy of the object whose security is to be ensured (enterprise, state, group of states, world, individual, family, etc.) is not endangered by threats which significantly reduce or could reduce its performance efficiency necessary for ensuring the defence as well as other security capacities, social reconciliation and competitiveness of the object and its individual components (especially individual companies) on the internal as well as external markets.

However, the economic security can be also viewed from another angle. Then, the economic security can be defined as security of economic subjects, processes and relations between them but, at the same time, it can be perceived as sustainability of the given processes and relations between the economic subjects

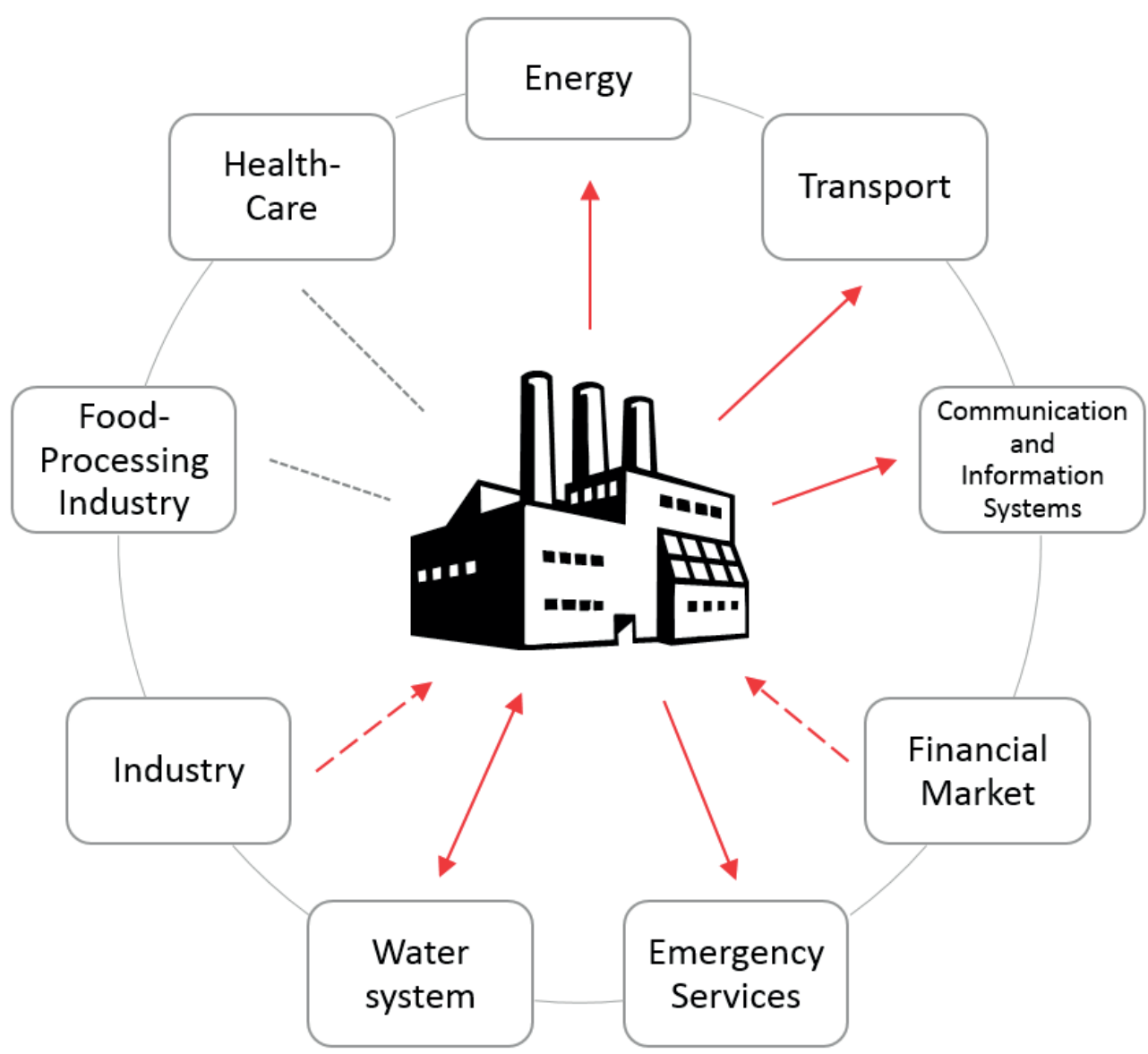

Legend:

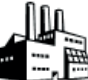

Medium-sized manufacturing industrial enterprise $---\rightarrow$

Influence of critical infrastructure sector on the company

Dependence of the company on the critical infrastructure sector

Interdependence of critical infrastructure sector and the company

There is no significant link between the critical infrastructure sector and the company 
in the sense of fulfilling the requirement of economy. However, it can be said the definitions of economic security (e.g. [7], [8] and [9] and [10]) are more oriented on protecting ourselves against effects of negative influences than detecting the economy of means which is expended.

The enterprise perceives economic security, on the one hand, from the point of view of ensuring sufficient resources for realising activities in routine as well as emergency conditions and, on the other hand, from the point of view of return of the means invested.

Not only money in cash or other financial assets are understood under the means for doing business but also other enterprise manufacturing factors (workforce, long-term tangible and intangible assets, short-term material assets) and links between them. We call them sources of economic security. They can be divided into two basic groups:

- material resources of enterprise economic security:

- financial resources of the enterprise economic security (enterprise capital) which the enterprise gains from its own or outside financial resources and utilises it for its entrepreneurial activity [11] and [12],

- natural resources of the enterprise economic security buildings, manufacturing and other equipment, means of transport, estates, inventories and energy or material components of the long-term and short-term assets used in the entrepreneurial activity or ensure space for its realisation [13],

- intangible sources of the enterprise economic security human abilities, information, technologies utilised, management system, patents, licenses, know-how but also the enterprise reputation [14]

The task of the enterprise management (in relation to maintaining the economic security) is to choose and make use of employees, manufacturing equipment, technologies and other sources in a way which will ensure the highest productivity of work [15]. At the same time it has to take into account the fact that excessive utilisation of these factors can result in failures and losses of the property, health and possibly also lives. Besides, it has to respect external conditions in which the enterprise realises its activities and take measures preventing any reduction of the enterprise performance efficiency.

\section{Threats disrupting the enterprise economic security}

The economic security of an enterprise is influenced by a complex of factors which affect the enterprise in the same time. These factors result in threats for the enterprise which can be classified as internal and external ones (see Fig. 2).

The internal threats result from the activity of the enterprise itself and consists of items such as an unsuitable structure of capital and assets, insolvency, inability to maintain the ownership structure, the character and development of the transformation process (production, warehousing, sale), intentional or unintentional errors caused by employees, process and management failures, shortages and errors in the area of concluding contracts, information explosion, etc. [16]. As the figure shows, these threats can be classified as process, personal and actual ones.

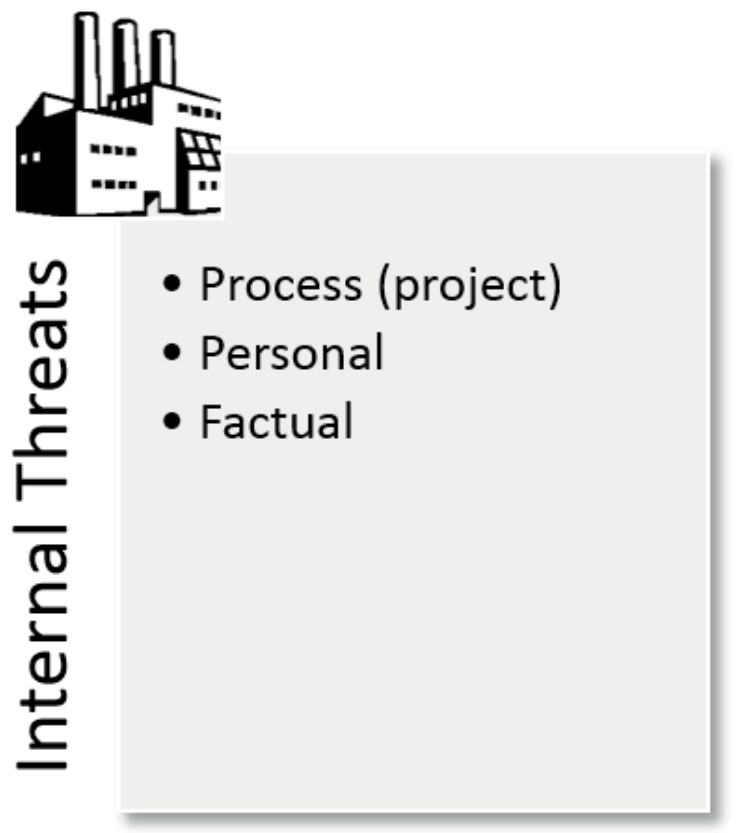

Fig. 2 Classification of threats disrupting the enterprise economic security 
The external threats impact the enterprise from its surroundings. Here belong competition, disruption of confidentiality, accessibility and integrity of information, corruption, situation on the financial market, exchange rate risk, act of sabotage, espionage [17], demographic and educational structure, industrial accidents, geophysical and climatological phenomena, etc. A lot of these threats endanger the economic security of other market subjects or affect other components of the complex security model.

The failure of some critical infrastructure elements (e.g. failure of financial market, supplies of energy or communication and information systems) which can cause direct or indirect disruptions of supplying resources to the enterprise represents a significant external threat for the enterprise economic security.

\section{Impacts of critical infrastructure failure on enterprise economic security}

Disturbances and subsequent failures of the critical infrastructure can be connected with physical and chemical processes (corrosion, wear) but also with inappropriate management and projects [18]. Even if the disturbances are natural, more modern technologies are developed and they are more complicated and are typical in a network structure which increases the risk of a failure. Therefore, it is important for every country to possess an efficient system of effective assessment of the critical infrastructure element protection [19] and [20].

Three basic types of failures which have a negative impact on the enterprise economic security can develop in the framework of the critical infrastructure [21]. The first type is the cascade failure when a breakdown in one infrastructure is the cause of a failure of an element or subsystem in another infrastructure and this fact arouses non-functionality of such an infrastructure. E.g. Beccuti et al. [22] deals with the area of quantifying dependences between electrical and information infrastructures. The escalating failure is another type - a failure in one infrastructure deteriorates the failure parameters in another infrastructure. The last type is the join failure when two and more infrastructures have a breakdown at the same time and these failures have a similar cause (this type mostly evolves due to natural disasters).

Based on the aforementioned explanations, the impact of the critical infrastructure failures on the enterprise economic security can be classified according to their significance as follows:

- insignificant (they do not disrupt the enterprise economic security) - these impacts are early identified in the framework of the risk analysis and subsequently security measures to minimise them are taken,

- significant (they disrupt the enterprise economic security) these impacts are also identified in the framework of the risk analysis, however, their minimisation is demanding from the point of view of time or costs,

- critical/fatal (they threaten the existence of the enterprise) these impacts were either identified late or the enterprise has not enough means (financial, material, personnel) for their minimisation.

The nature of the critical infrastructure failure on enterprise economic security is a significant factor for determining the importance of the impacts. The nature of the impacts is characterised by four basic values which are closely connected to each other and create information about the extent of potential damages in the enterprise (see Fig. 3).

The first, and most significant, value is the area of the impact performance. The impacts affecting the sources of the economic security can negatively influence the financial resources (e.g. due to the failure of the financial market), the natural resources (e.g. due to the failure of the energy supply) or non-material resources (e.g. due to failure of the communication and information systems).

The second value characterising the nature of the impacts is the structure of their performance. From this point of view the impacts can be classified as direct, i.e. directly affecting the enterprise economic security (e.g. impacts caused by artificial devaluation of the national currency) or indirect, i.e. impacts affecting the enterprise economic security secondarily or tertiary (e.g. impacts due to power blackout).

\section{Impact character}

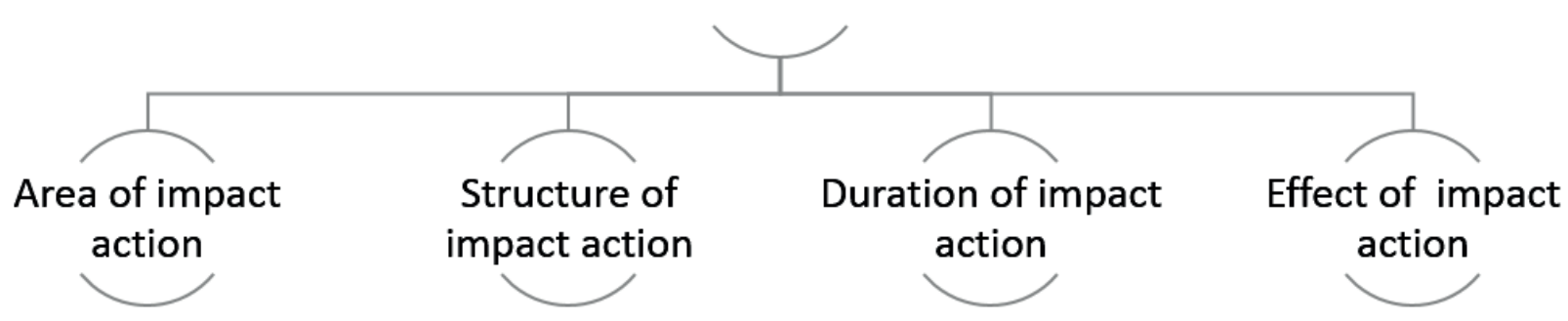

Fig. 3 Values characterising the nature of impacts of critical infrastructure failure on enterprise economic security 
The third value which determines the nature of the impacts is duration. If it is only a short-term duration (e.g. power failure taking one hour) the enterprise suffers almost no losses. In the case of a medium-term duration of impact action (i.e. a few days) the losses are considerable; however, the enterprise is able to compensate them from the reserve resources. If the impacts are of a long-term character (i.e. months - the natural gas crisis in January 2009, when its impacts were visible especially in Slovakia and Bulgaria [23], can serve here as an example) the losses cumulate and even increase rapidly. In such a case the crisis scenarios are activated and the existence of the enterprise can be endangered.

The last value characterising the nature of the impacts is their effect. From this point of view the effect of the impacts can be defined as a single-way one, i.e. caused by failing one sector of the critical infrastructure or a multi-way one, i.e. caused by parallel or cascade failure of two or more sectors of the critical infrastructure (e.g. power failure, subsequently the communication and information systems fail and this results in limiting the accessibility of emergency services).

\section{References}

[1] DAIDO, K., TABATA, K.: Public Infrastructure, Production Organization, and Economic Development. J. of Macroeconomics, vol. 38, No. Part B, 2013, pp. 330-346, ISSN 0164-0704.

[2] Council of the European Union, Council Directive 2008/114/EC of 8 December 2008 on the Identification and Designation of European Critical Infra-structures and the Assessment of the Need to Improve their Protection.

[3] KELISEK, A., KLUCKA, J., ONDRUSEK, M., STRELCOVA, S.: Economic Security: A Principal Component of Multilevel Security Concept in Global Economy. Communications - Scientific Letters of the University of Zilina, vol. 13, No. 2, 2011, pp. 44-48, ISSN 1335-4205.

[4] Act No. 45 from 8 February 2011 on Critical Infrastructure (in Slovak).

[5] Government Decree ) No 432 from December 222010 on Criteria for Determination of the Critical Infrastructure Element (in Czech), 2010.

[6] ZEMAN, P. et al.: Czech Safety and Security Terminology (in Czech), $1^{\text {st }}$ ed., Brno : Masaryk University, 2003, 186 p. ISBN 80-210$3037-2$.

[7] BUSINESS DICTIONARY: Economic Security [online]. [cit. 2014-08-28] Available at: http://www.businessdictionary.com/ definition/economic-security.html

[8] INTERNATIONAL COMMITTEE OF THE RED CROSS: Ensuring Economic Security [online]. [cit. 2014-08-28]. Available at: https://www.icrc.org/en/what-we-do/ensuring-economic-security

[9] INTERNATIONAL LABOUR ORGANIZATION: What we Mean when we Say "Economic Security " [online]. [cit. 2010-11-11]. Available at: http://www.ilo. org/public/english/protection/ses/download/docs/definition.pdf

[10] WEller, C., LOGAN, A.: Measuring Middle Class Economic Security. J. of Economic Issues, vol. 43, No. 2, 2009, pp. 327-336, ISSN 0021-3624, DOI: 10.2753/JEI0021-3624430205

[11] VLACHYNSKY, K. et al.: Corporate Finance (in Slovak), Bratislava : Iura Edition, 2006, 482 p. ISBN 80-8078-029-3.

[12] IVANCHENKO, N. O.: Semantic Modelling of Technical-technological Functional Constituent of Enterprise Economic Security. Actual Problems of Economics, vol. 127, No. 1, 2012, pp. 276-282, ISSN 1993-6788.

[13] KUPKOVIC, M. et al.: Business Economics (in Slovak), Bratislava : Sprint vfra, 2003. 452 p., ISBN 80-88848-71-7. 
[14] STRELCOVA, S.: Economic Security of Enterprise (in Slovak), [online]. Security Revue: Inter. Magazine for Security Engineering, 2012. ISSN 1336-9717 [cit. 2014-08-28]. Available at: http://www.securityrevue.com/article/2012/10/ekonomicka-bezpecnostpodniku/.

[15] BERNANKE, B.S.: Skills, Ownership, and Economic Security. Economists'Voice, vol. 3, No. 2, 2006, pp. 1-6, ISSN $1553-3832$.

[16] CHOD, J., ZHOU, J.: Resource Flexibility and Capital Structure. Management Science, vol. 60, No. 3, 2014, pp. 708-729, ISSN 0025-1909, DOI: $10.1287 /$ mnsc.2013.1777

[17] SINHA, S.: Understanding Industrial Espionage for Greater Technological and Economic Security. IEEE Potentials, vol. 31, No. 3, 2012, Article No 6193307, pp. 37-41, ISSN 0278-6648, DOI: 10.1109/MPOT.2012.2187118

[18] SENOVSKY, M., SENOVSKY, P.: Critical Infrastructure Risks. Communications - Scientific Letters of the University of Zilina, vol. 10, No. 1, 2008, pp. 54-59, ISSN 1335-4205.

[19] HROMADA, M., LUKAS, L.: Multicriterial Evaluation of Critical Infrastructure Element Protection in Czech Republic. Communications in Computer and Information Science, vol. 340, No. CCIS, pp. 361-368, ISSN 1865-0929, ISBN 978-364235266-9. DOI: 10.1007/978-3-642-35267-6_48.

[20] LOVECEK, T., RISTVEJ, J., SIMAK, L.: Critical Infrastructure Protection Systems Effectiveness Evaluation. J. of Homeland Security and Emergency Management, 2010, Vol. 7, Iss. 1, Article 34, ISSN 1547-7355. DOI: 10.2202/1547-7355.1613 Available at: http://www.bepress.com/jhsem/vol7/iss $1 / 34$

[21] RINALDI, S. M., PEERENBOOM, J. P., KELLY, T. K.: Identifying, Understanding and Analyzing Critical Infrastructure Interdependencies. IEEE Control Systems Magazine, 2001, 21(6):11-25.

[22] BECCUTI, M., CHIARADONNA, S., DI GIANDOMENICO, F., DONATELLI, S., DONDOSSOLA, G., FRANCESCHINIS, G.: Quantification of Dependencies between Electrical and Information Infrastructures. Intern. J. of Critical Infrastructure Protection, vol. 5, No. 1, 2012, pp. 14-27, ISSN 1874-5482, DOI: 10.1016/j.ijcip.2012.01.003

[23] Commission Staff Working Document, Accompanying Document to the Proposal for a Regulation of the European Parliament and of the Council Concerning Measures to Safeguard Security of Gas Supply and Repealing Directive 2004/67/EC, 'The January 2009 Gas Supply Disruption to the EU: An Assessment' COM(2009) 363, Brussels, SEC(2009) 977 final, 16 July 2009.

[24] REHAK, D., GRASSEOVA, M.: The Ways of Assessing the Security of Organization Information Systems through SWOT Analysis, pp. 162-184, DOI: 10.4018/978-1-61350-311-9.ch007. In ALSHAWI, Mustafa, ARIF, Mohammed (eds.). Cases on E-Readiness and Information Systems Management in Organizations: Tools for Maximizing Strategic Alignment. $1^{\text {st }}$ edition. Hershey, IGI Global, 2011, 318 p. ISBN 978-1-61350-311-9, DOI: 10.4018/978-1-61350-311-9

[25] GRASSEOVA, M., DUBEC, R., REHAK, D.: Analysis of the Enterprise at the Hands of Managers: 33 Most Frequently Applied Methods of the Strategic Management (in Czech), 1 1 ${ }^{\text {st }}$ ed., Brno : Computer Press, 2010, 325 p. ISBN 978-80-251-2621-9. 